\title{
Effect of Concentration of Mica on Properties of Polyester Thermoplastic Elastomer Composites
}

\author{
M. S. Sreekanth ${ }^{1}$, V. A. Bambole ${ }^{2}$, S. T. Mhaske ${ }^{1}$, P. A. Mahanwar ${ }^{1 *}$ \\ 1. Department Polymer Engineering \& Technology \\ 2. Department of Applied Physics \\ Institute of Chemical Technology, \\ Matunga, Mumbai-400019, India \\ *Corresponding Author, contact: pmahanwar@yahoo.com \\ Phone: +91-22-24145616, Fax: +91-22-24145616
}

\begin{abstract}
Particulate filled polymer composites are becoming attractive because of their wide applications and low cost. In this study the effects of mica with varying concentration on the mechanical, thermal, electrical, rheological and morphological properties of polyester thermoplastic elastomer (Hytrel ${ }^{\circledR}$ ) was investigated. Composites of Hytrel ${ }^{\circledR}$ with varying concentrations (viz. 5 to 40 weight \%) of mica were prepared by twin screw extrusion. Mechanical properties such as flexural strength and modulus were found to increase with mica concentration, whereas tensile strength was found to decrease at higher concentrations. Electrical and thermal properties of composite were found to increase with filler concentration. Morphological studies revealed that there is a good dispersion of filler in the polymer matrix at lower concentrations.
\end{abstract}

\section{INTRODUCTION}

The performance of filled polymers is generally determined on the basis of the interface attraction of filler and polymers. Incorporating inorganic mineral fillers [1] into plastic resin improves various physical properties of the materials such as mechanical strength, modulus etc. In general the mechanical properties [2] of particulate filled polymer composites depend strongly on size, shape and distribution of filler particles in the polymer matrix and extent of interfacial adhesion between filler and matrix. 
Thermoplastic elastomers [3] are an important class of engineering thermoplastic elastomers, combines the physical properties of elastomers with the excellent processing characteristics of thermoplastics. A family of novel segmented polyester thermoplastic elastomer has been developed by du Pont under the trade-mark Hytrel ${ }^{\circledR}$. Polyester thermoplastic elastomer consisting of poly(butylene terephthalate) (PBT), as hard segments and poly(tetramethylene ether glycol terephthalate) as soft segments. The basic structure of polyester thermoplastic elastomer is shown in scheme-1. Polyester thermoplastic elastomer shows outstanding mechanical properties [4,5] at temperatures up to $130^{\circ} \mathrm{C}$ coupled with very good low temperature flexibility. It shows good resistance to tear, impact, abrasion and creep and excellent oil, hydraulic fluids and grease resistance. In order to improve thermal, mechanical and electrical properties of polyester thermoplastic elastomers [6], particulate fillers such as alumina trihydrate, montmorillonite, clays, talc, mica, silica, flyash, wollastonite, kaolin etc are incorporated. Flakes or platelets represent a special class of reinforcing fillers for thermoplastics and thermosets. Mica [7] is one such type of filler and is a particularly abundant mineral. Mica [8] had been a widely studied filler due to its unique set of properties.

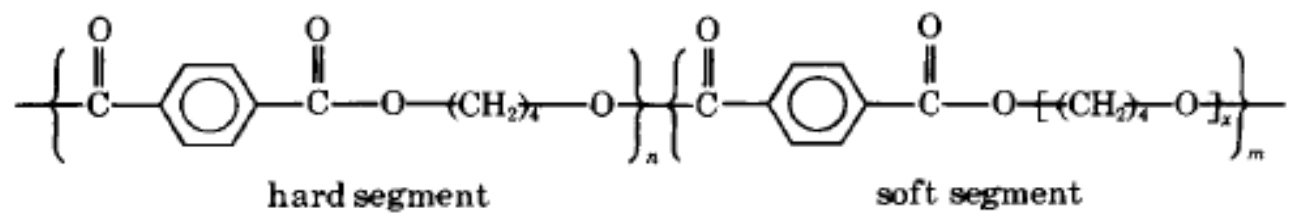

Scheme-1: Structure of Hytrel ${ }^{\circledR}$

Recently the effect of mica on properties of thermoplastic elastomers [9-10] and engineering thermoplastics [11-13] have been investigated extensively. Mica has an outstanding mechanical, thermal, electrical and chemical properties rarely found in any other products. Mica [7] provides cost effective improvements in the critical properties for a wide range of thermoplastic and thermoset composites. Polyester thermoplastic elastomer composites are mainly used in a wide variety of automotive parts such as gears and sprockets [5]. It is also used in high strength industrial hoses and tubing [14-15] and also in shock damping applications In the present work we studied the effect of mica of varying concentration [8] on the properties of polyester thermoplastic elastomer. The detail list of materials used is given in Table 1.

\section{EXPERIMENTAL}

\subsection{Compounding}

The matrix and filler were predried prior to the compounding. Polyester thermoplastic elastomer and mica were dried at $80^{\circ} \mathrm{C}$ for 6 hours in an air circulated oven and both of them are dry blended to a uniform physical dispersion of polymer and filler. The following composition of 
filler (viz. 5 to 40 weights \%) was mixed and extruded in a co-rotating twin extruder (APV Baker Ltd. England, Model: MP19PC). The L/D ratio of the screw is 25:1. Mixing speed of $60 \mathrm{rpm}$ was maintained for all the compositions. The extrudates from the die were quenched in a tank at 20$25{ }^{0} \mathrm{C}$ and then pelletized. For the melt blending the temperature profile of the extrusion were as follows: Zone $1\left(120{ }^{\circ} \mathrm{C}\right)$, Zone $2\left(180{ }^{0} \mathrm{C}\right)$, Zone $3\left(210{ }^{0} \mathrm{C}\right)$, Zone $4\left(225{ }^{\circ} \mathrm{C}\right)$ and Die $\left(240{ }^{0} \mathrm{C}\right)$. The extrudates of the compositions were palletized in Boolani's pelletizing machine. The speed of the pelletizer was maintained between the ranges of 2-3 rpm.

Table 1 Materials used

\begin{tabular}{|c|c|c|l|}
\hline Materials used & Function & Grade & \multicolumn{1}{|c|}{ Suppliers } \\
\hline Polyester TPE & Polymer matrix & Hytrel 6356 & $\begin{array}{l}\text { M/S Rupal Plastics } \\
\text { Ltd, Mumbai, India }\end{array}$ \\
\hline Mica & Filler & Wet Ground(50 $\mu)$ & $\begin{array}{l}\text { Galaxy Corporation } \\
\text { Mumbai, India }\end{array}$ \\
\hline
\end{tabular}

\subsection{Injection Molding}

The granules of the extrudates were predried in an air circulated oven at $80^{\circ} \mathrm{C}$ for 8 hours and injection molded in a microprocessor based Boolani's injection moulding machine fitted with a master mould containing the cavity for tensile strength, flexural and impact specimens. After its ejection from the mould, specimens were cooled in ice-water. Processing parameters are: Zone 1 $\left(150{ }^{\circ} \mathrm{C}\right)$, Zone $2\left(225^{\circ} \mathrm{C}\right)$ and Zone $3\left(245^{\circ} \mathrm{C}\right)$.

\subsection{Characterization}

\subsubsection{Mechanical properties}

Tensile strength as per ASTM D638 M91 was evaluated using universal tensile testing machine LR50K from Lloyd instruments Ltd., U.K at a crosshead speed of $50 \mathrm{~mm} / \mathrm{min}$. Flexural properties according to ASTM D790 were tested using LR 50K from Lloyd instruments Ltd., U.K. Izod impact tests were carried out using an Avery Denison impact tester (ASTM D256-92). A $5.0 \mathrm{~J}$ energy hammer was used and the striking velocity was $3.46 \mathrm{~m} / \mathrm{sec}$. For Izod impact test specimens, the notch was cut using a motorized notch- cutting machine (Rayran U.K). The unit of expression is $\mathrm{J} / \mathrm{m}^{2}$. 


\subsubsection{Electrical properties}

The Dielectric Strength, according to ASTM D 149, was measured using Zaran Instruments (India) with a $2 \mathrm{~mm}$ thick composite disc. The voltage was increased slowly and the voltage at which the current penetrated the sample was noted. The configurations of the instruments were: input: $240 \mathrm{~V}, 50 \mathrm{~Hz}, 1 \mathrm{PH}$; output: 0-50 kV; capacity: $100 \mathrm{~mA}$; rating: $15 \mathrm{~min}$.

\subsubsection{Thermal properties}

DSC is used to study the thermal properties of the composites. DSC measurements were performed using TA Q100 analyzer (TA Instruments, U.S.). The weight of sample was between 6 to $9 \mathrm{mg}$ in a standard aluminium pan.

\subsubsection{Rheological properties}

The melt rheology of the polymer and the composites were studied using a rotational rheometer (Haake RT 10, Germany), employing a parallel plate assembly, diameter $35 \mathrm{~mm}$, at $250^{\circ} \mathrm{C}$. The samples were predried before analysis. The shear rate range was varied from $1-100 \mathrm{~s}^{-1}$. Melt viscosity, $\eta$ (Pa s) as a function of shear rate, $\gamma(1 / \mathrm{s})$ was recorded.

\subsubsection{Morphological properties}

SEM is used to study the morphology of the composites. SEM studies of fractured impact samples were carried out on a Cameca SU-SEM probe. The accelerated voltage used was $15 \mathrm{kV}$. Samples were sputter-coated with gold to increase surface conductivity. The digitized images were recorded.

\section{RESULTS AND DISCUSSION}

\subsection{Tensile Properties}

Fig. 1 shows the variation of tensile strength [2] as a function of mica in wt $\%$. After a moderate increment in the initial concentration of mica, the tensile strength decreases at higher filler concentrations. The increment [8] may be due to the platy structure of the mica providing good reinforcement. As the filler concentration increases mica platelets tend to aggregate and the tensile strength decreases. Elongation properties as seen from Fig. 2 decreased with the addition of filler indicating interference by the filler in the mobility or deformability of the matrix. This interference is created through the physical interaction and immobilization of the polymer matrix by the presence of mechanical restraints. So as the filler concentration increases the elongation at break get reduced. 


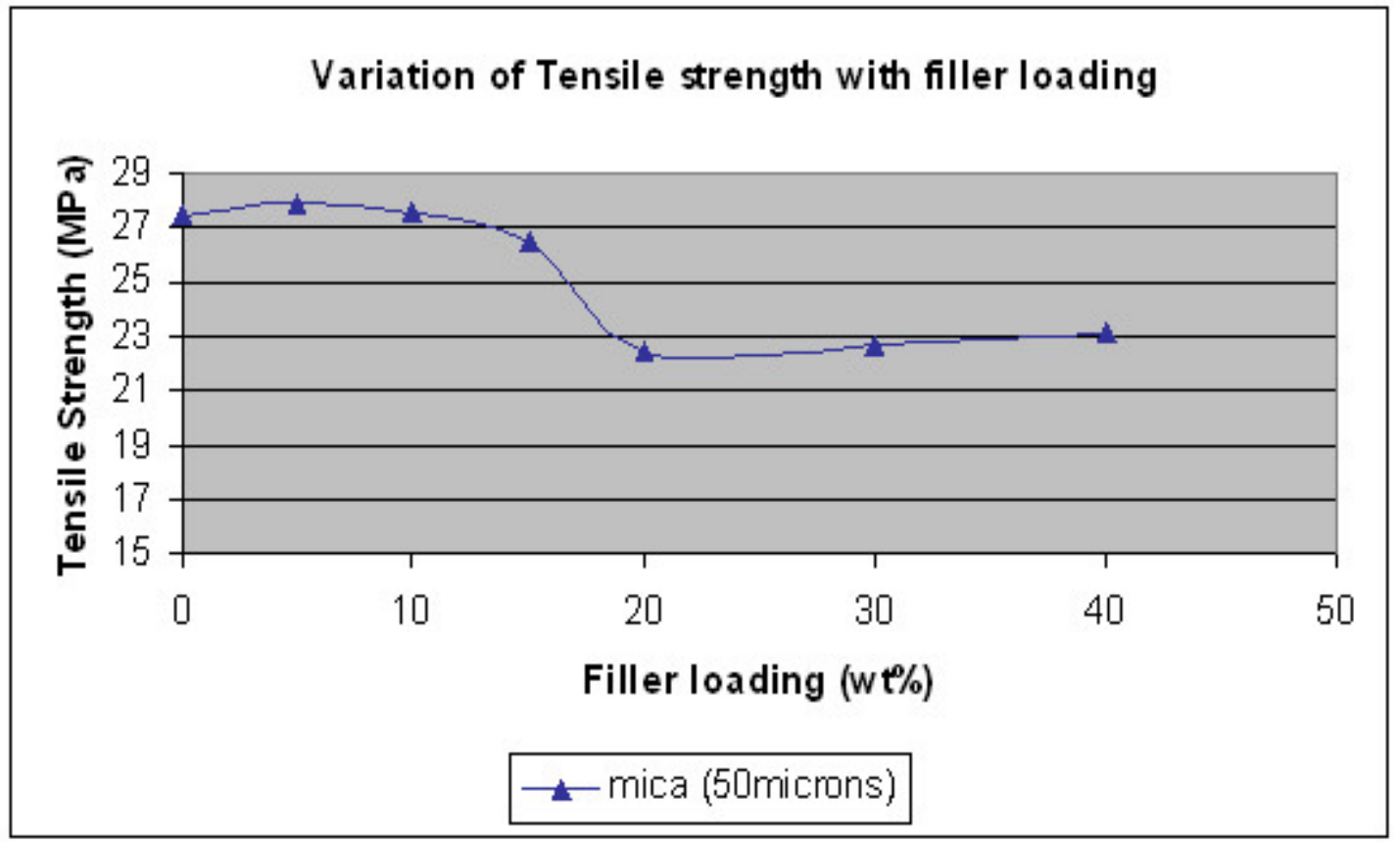

Figure 1. Variation of the Tensile Strength of Polyester Thermoplastic Elastomer with Mica Concentration

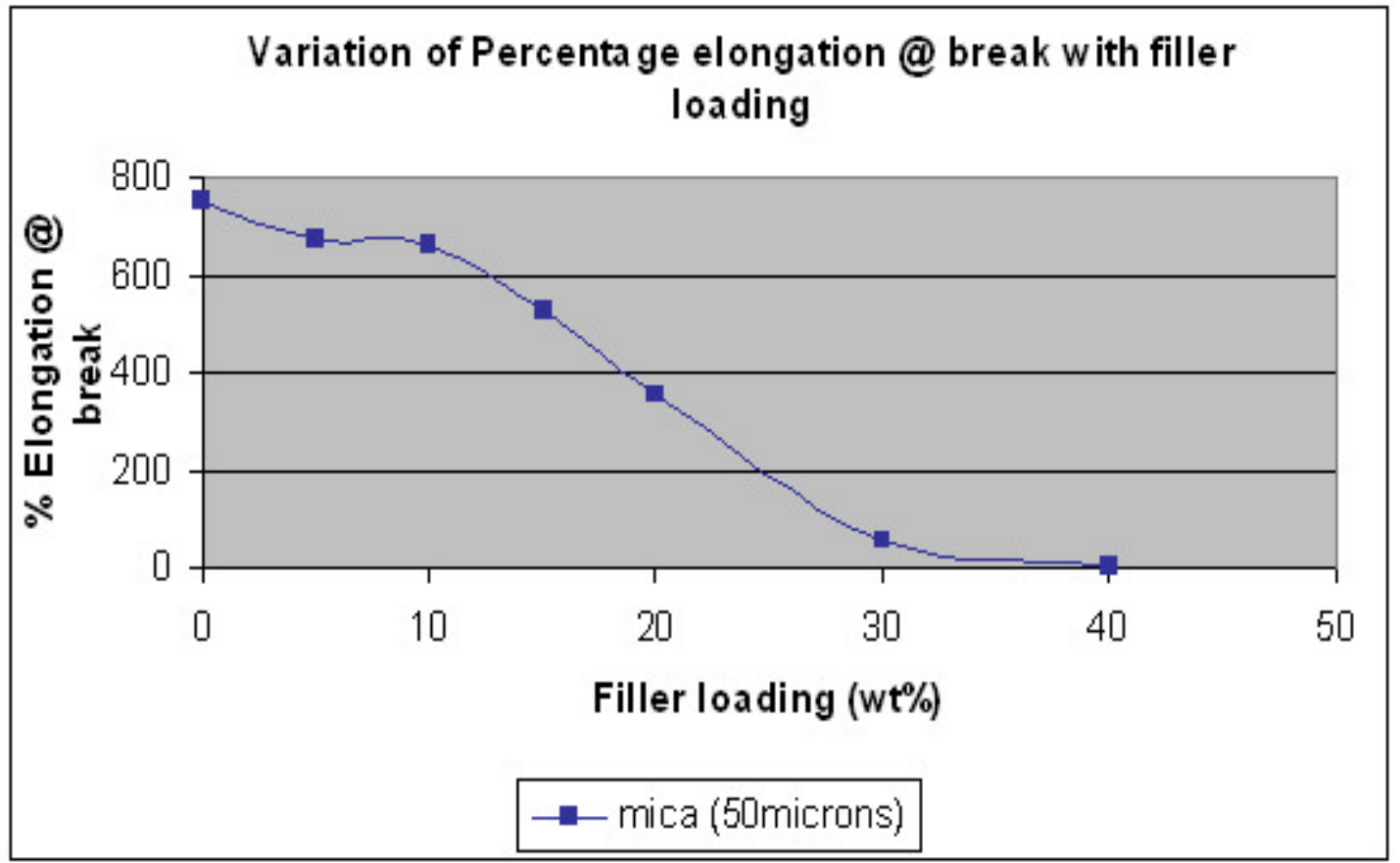

Figure 2. Variation of the Elongation at break of Polyester Thermoplastic Elastomer with Mica Concentration 


\subsection{Flexural Properties}

Fig. 3 shows the variation in flexural strength with varying concentration of mica. The flexural strength of composites increases with increase in concentration of mica. There is a significant increase in the flexural strength with increasing concentration of mica as shown in the figure. It is worth pointing out that the total area for deformation stress also has an important role in flexural properties. Flexural modulus [16] as shown in Fig. 4 is found to increase with increase in concentration of mica.

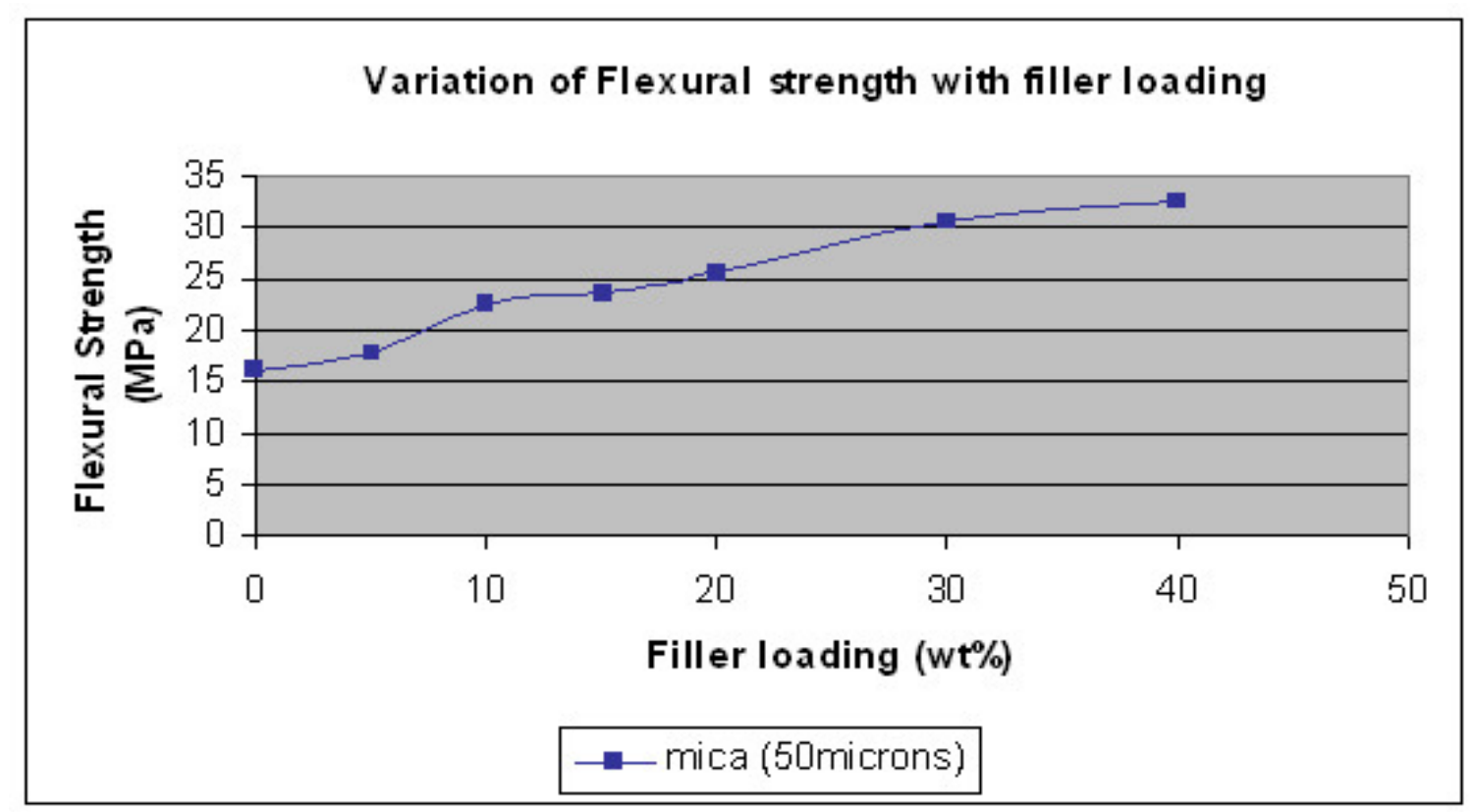

Figure 3. Variation of the Flexural strength of Polyester Thermoplastic Elastomer with Mica Concentration

\subsection{Impact Strength}

Fig. 5 illustrates the variation of impact strength with mica loading. It is clear from the figure that the impact strength decreases with filler addition. This is mainly due to the reduction of elasticity [8] of material due to filler addition and thereby reducing the deformability of matrix and in turn the ductility in the skin area, so that the composite tend to form a weak structure. An increase in concentration of filler reduces the ability of matrix to absorb energy and thereby reducing the toughness, so impact strength decreases. 


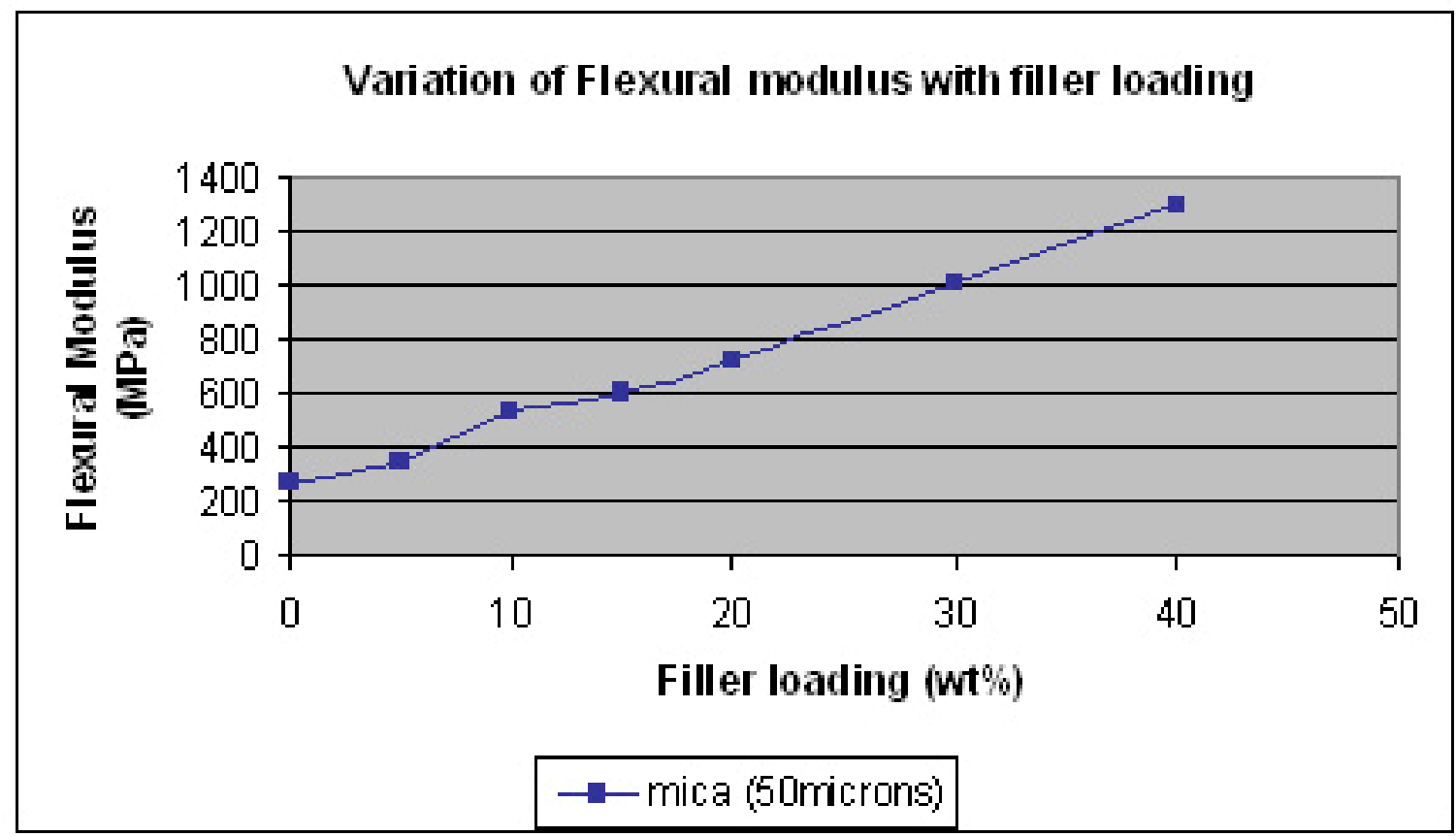

Figure 4. Variation of the Flexural modulus of Polyester Thermoplastic Elastomer with Mica Concentration

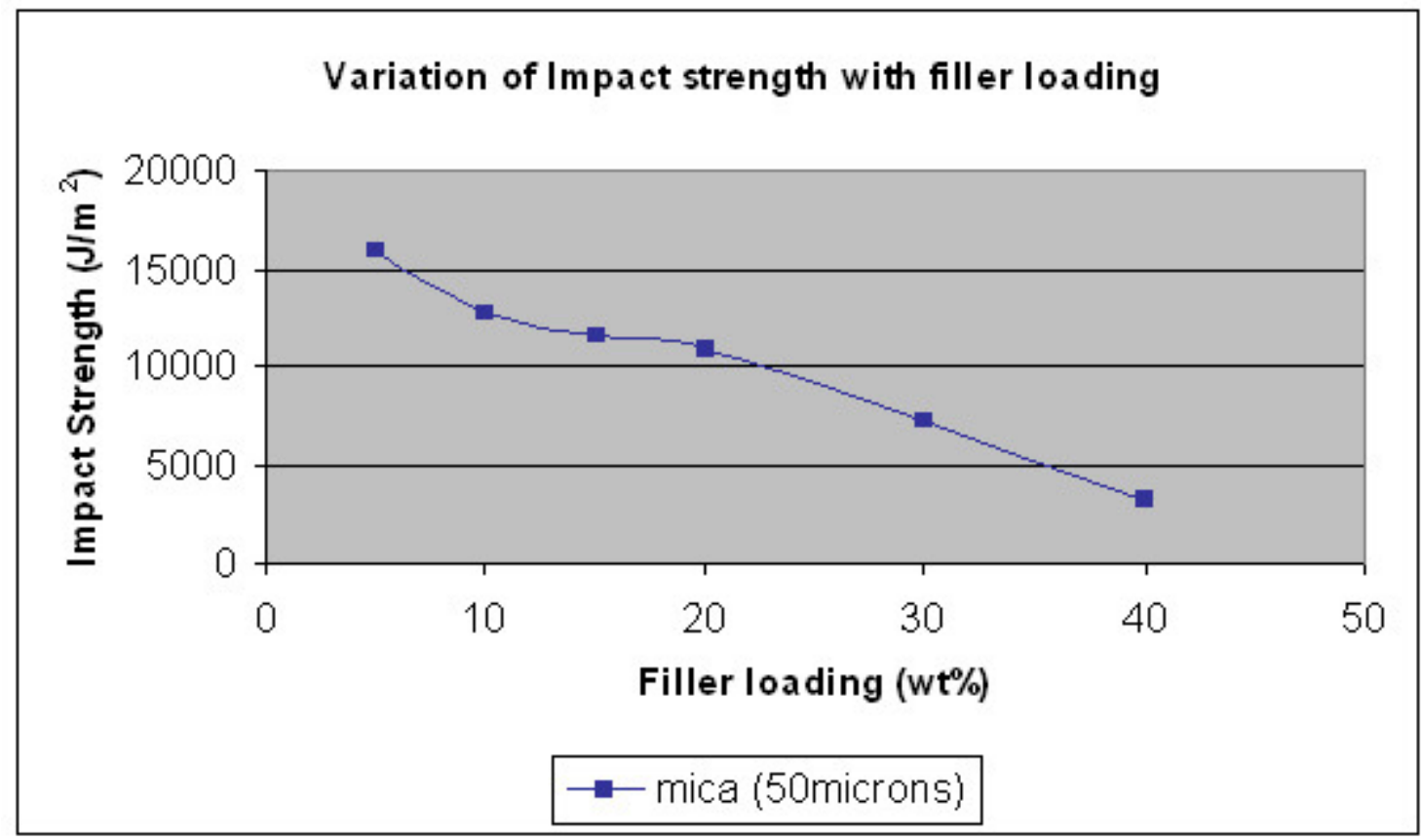

Figure 5. Variation of the Impact Strength of Polyester Thermoplastic Elastomer with Mica Concentration 


\subsection{Dielectric Strength}

It is clear from Fig. 6 that the dielectric strength increased with the increase in mica concentration and attained maxima. At higher filler loading the dielectric strength values remained almost constants with the increase in filler. This trend in variation of dielectric strength in mica is attributed to the total surface area available from the filler as well as its continuity. The dielectric strength values showed better for higher particle size of mica.

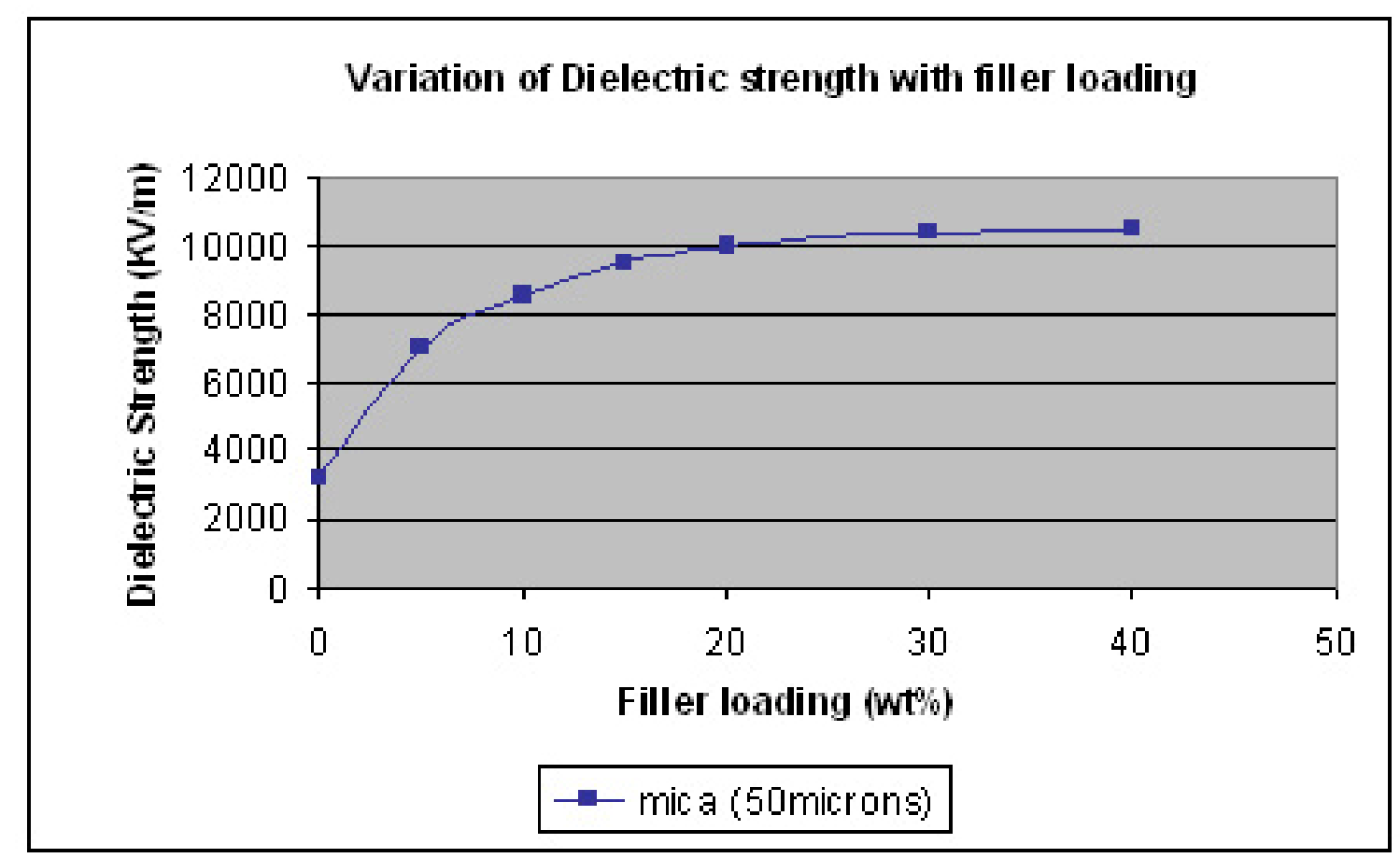

Figure 6. Variation of the Dielectric Strength of Polyester Thermoplastic Elastomer with Mica Concentration

\subsection{Thermal Properties}

The melting and the crystallization temperature of the composites were studied by using DSC. Fig. 7 shows the variation of melting temperature with filler addition. The matrix polymer showed a melting temperature around $211.95{ }^{\circ} \mathrm{C}$. With the addition of filler the melting point of composites increased up to 3 to $4{ }^{\circ} \mathrm{C}$ manifesting the fact that the addition of filler improves the thermal stability of composites. Fig. 8 shows the variation of crystallisation temperature with filler addition. The matrix polymer shows a crystallization temperature around $170.05{ }^{\circ} \mathrm{C}$. Further, mica acts as a nucleating agent manifesting in higher crystallization temperature in the composites. The increment is due to the small and uniform crystallite size distribution. 


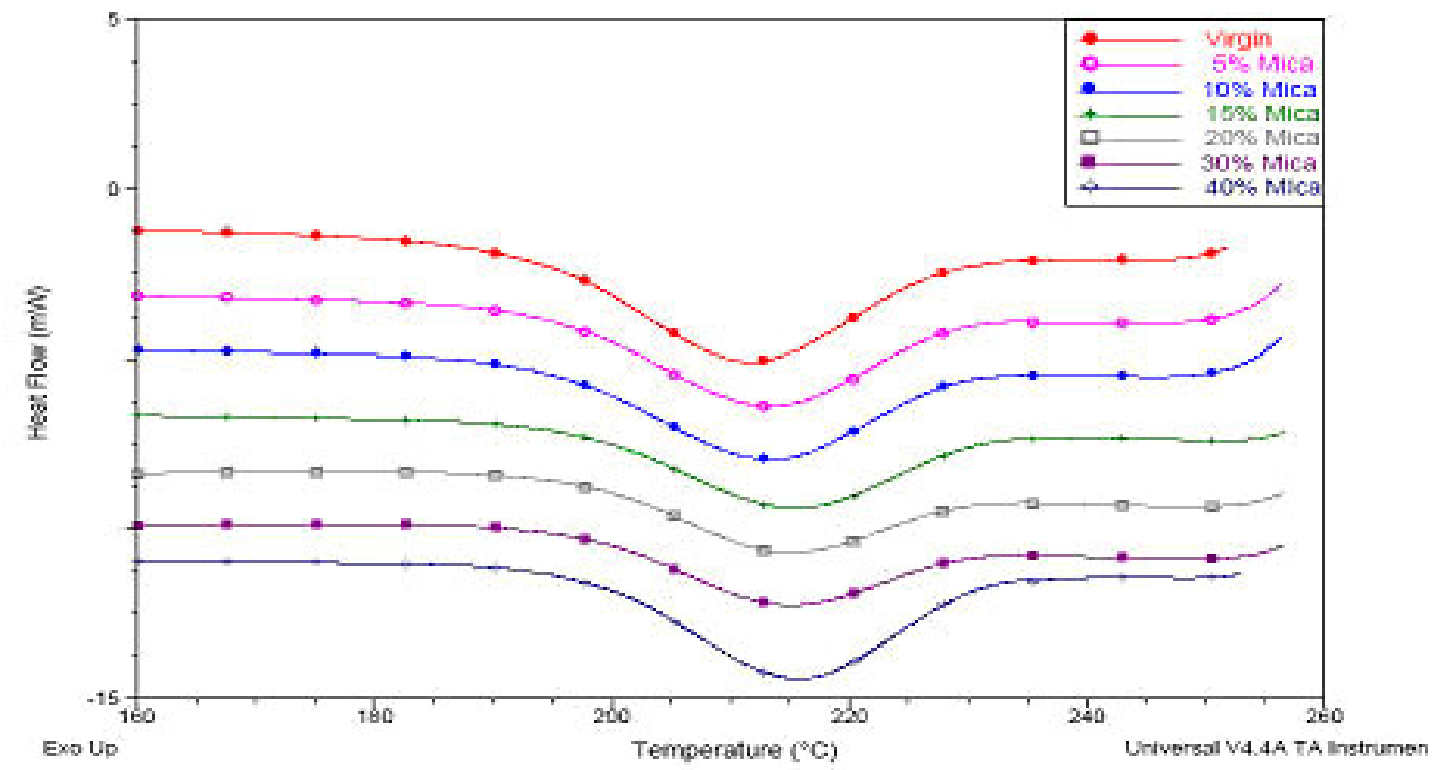

Figure 7. Variation of Melting Temperature of Polyester Thermoplastic Elastomer with Filler Concentration

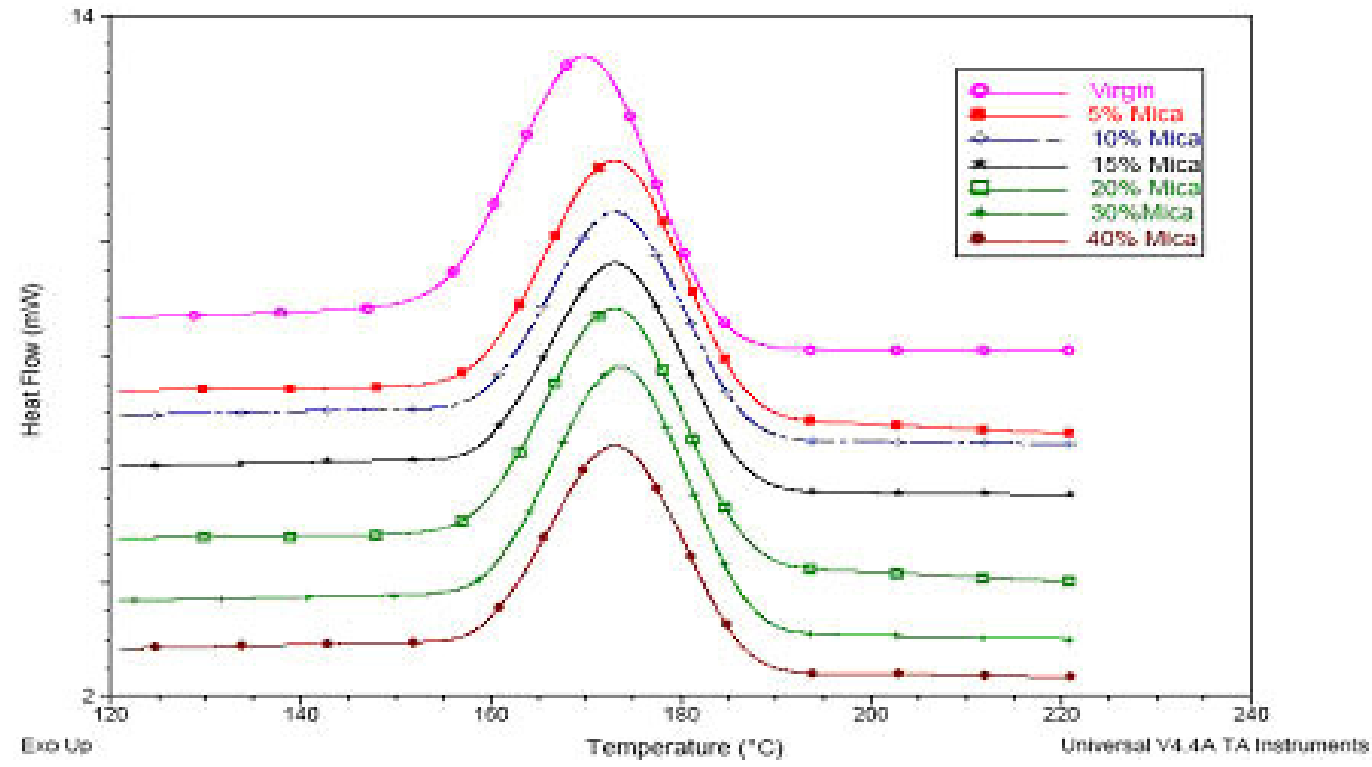

Figure 8. Variation of Crystallisation Temperature of Polyester Thermoplastic Elastomer with Mica Concentration 


\subsection{Rheological Properties}

Fig. 9 illustrates the variation of shear viscosity at $250{ }^{\circ} \mathrm{C}$ (in Pascal sec) with filler concentration at a shear rate at $0.1 \mathrm{sec}^{-1}$. Increase in the viscosity may be attributed to the properties of the filler such as maximum packing fraction. The increase in viscosity [17] was due to the ability of fine particles of filler particle to form a tight packing network. Rate of increase in the viscosity depended upon the ratio $(\varnothing / \varnothing \mu)$, where $\varnothing=$ vol. fraction of the filler and $\emptyset \mu=$ Max. packing fraction. Rheological study shows that with an increase in filler content the viscosity of the component increased.

\subsection{Morphological Properties}

SEM is used to study the morphology of composites. Fig. 10 shows the SEM micrographs of composites with $10 \%$ concentration of mica. Improved interaction between the filler and the matrix is inferred at lower concentration of filler (Fig.10). However, at higher concentrations, the interaction between the filler and the polymer gets reduced due to aggregation of the filler particles. The SEM images further exhibits that the mica platelets are aligned parallel to each other.

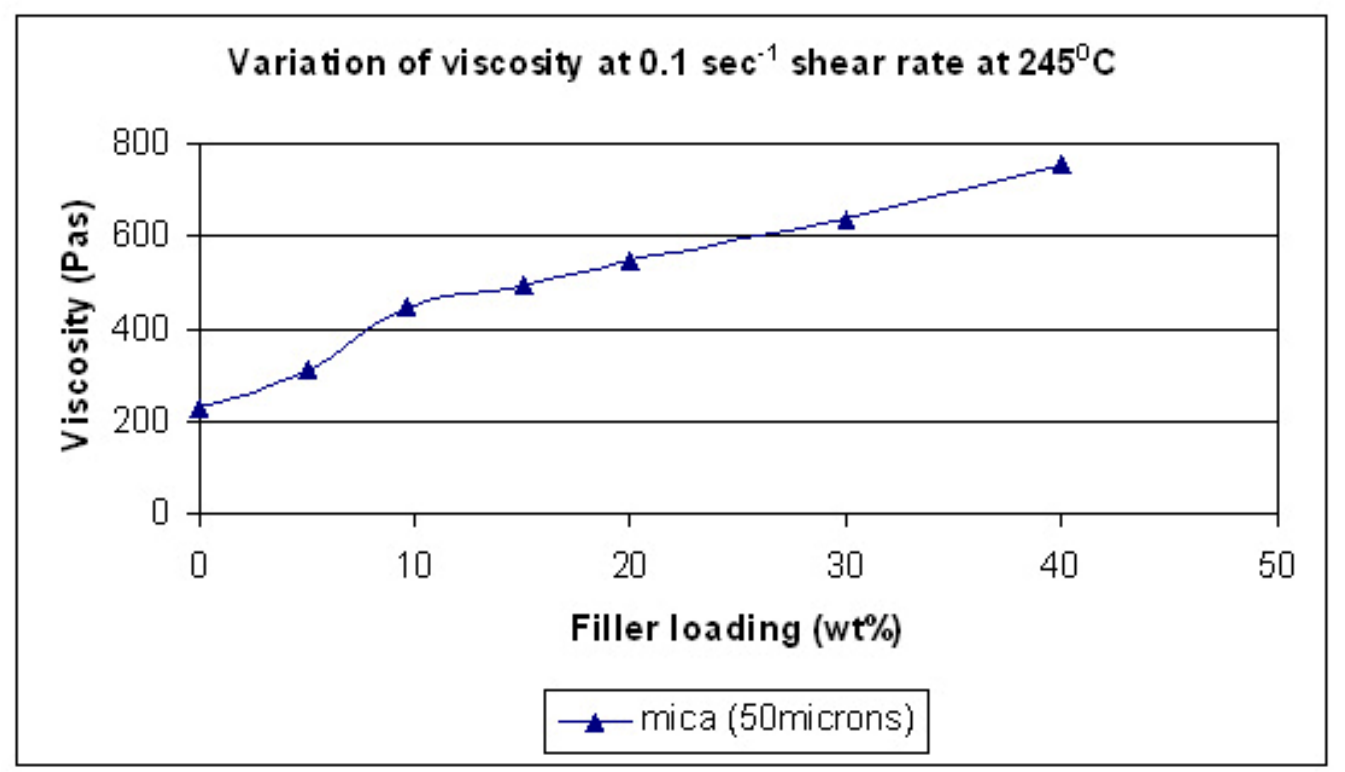

Figure 9. Variation of Shear Viscosity at 0.1 Shear rate at $245^{\circ} \mathrm{C}$ of Polyester Thermoplastic Elastomer with Mica Concentration 


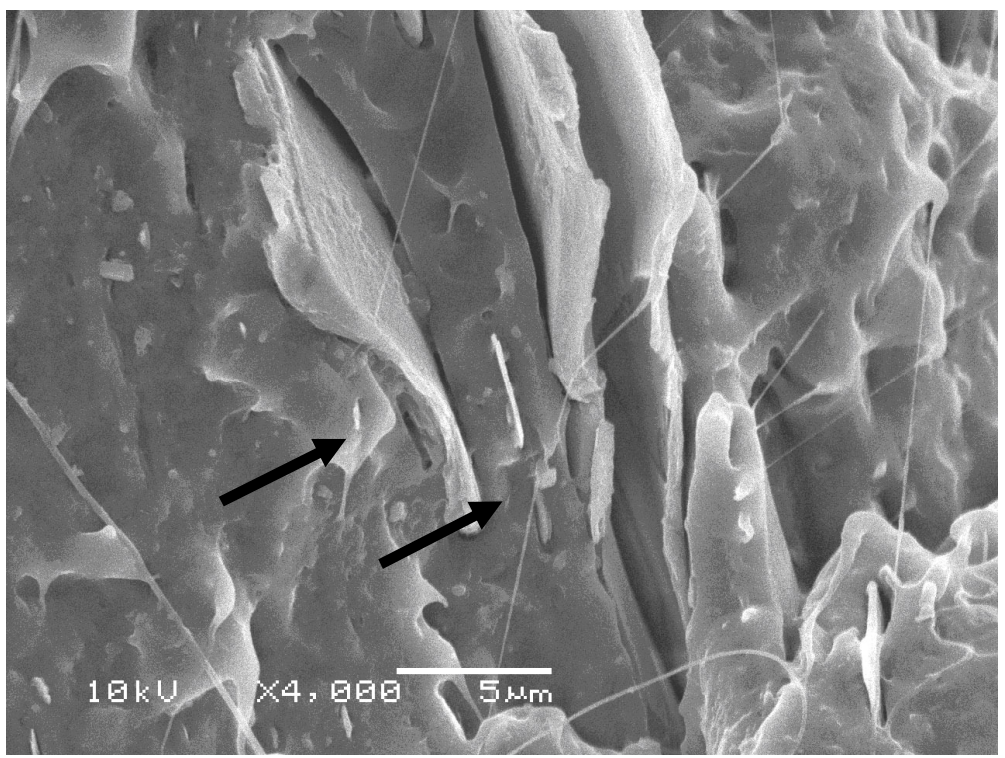

Figure10. SEM micrograph of Polyester Thermoplastic Elastomer with 10\% Concentration of Mica

\section{CONCLUSION}

Inorganic fillers viz. mica added to the polymer improved its rigidity, strength, and thermal stability, but dramatically decreased the elongation at break. There is a significant increment in the flexural strength and modulus with an increase in the filler concentration. The impact strength decreases with concentration of filler due to the reduction of elasticity of material due to filler addition and there by reducing the deformability of matrix. There is a significant increase in the dielectric strength with filler addition. Addition of mica improved the thermal properties of the composites due to small and uniform crystallite size distribution. Morphological studies showed that there is a better interaction between filler and the matrix at lower filler concentration and platelets are aligned parallel to each other. The mechanical properties of the composite were found to be a function of the particle size, aspect ratio, the dispersion, the particle orientation, the interfacial interaction between the minerals and the polymer matrix. Platy structured filler such as mica gave significant improvement in stiffness. It is concluded that the composite showed improved mechanical (flexural), thermal as well as electrical properties on addition of filler.

\section{REFERENCES}

[1] Katz, H.S., Milevski, J.V., 1978, Handbook of Fillers and Reinforcements for Plastics, Vol.1, ed.1, pp.333-457, Van Notrand Reinhold, New York.

[2] Unal, H., Findik, F., 2003, "Mechanical Behavior of Nylon Composites Containing Talc and Kaolin.” J.Appl Polym. Sci, Vol. 88, pp. 1694-1697. 
[3] Walker, B. M., 1979, Handbook of Thermoplastic Elastomer, Vol.1, ed.1, pp. 103-118, New York, Litton Education Publishing.

[4] Kaforglou, N. K., 1977, "Thermomechanical studies of semicrystalline polyether-ester copolymers." J.Appl Polym Sci, Vol. 21, pp. 543-554.

[5] Nagai, Y., Ogawa, T., Zhen, L. Y., 1997, "Analysis of weathering of thermoplastic elastomers." Polym. Degrad. Stab, Vol.56, pp. 115-121.

[6] Aso, O., Eguiazabal, J. I., Nazabal, J., 2007, "The influence of surface modification on the structure and properties of a nanosilica filled thermoplastic elastomer." Compo. Sci. Tech, Vol. 67, pp. 2854-2863.

[7] George, W., 1999, Mica, Handbook of Fillers, Vol. 1, ed. 2, pp. 112-115, Toronto, New York, Chem Tech Publishing.

[8] Bose, S., Mahanwar, P. A., 2004, "Effect of Particle Size of Filler on Properties of Nylon-6" J. Min .Mat .Char.\& Eng., Vol. 3, No.1, pp. 23-31.

[9] Baral, D., De, P. P., Nando, G. B., 1999, "Thermal characterisation of mica filled thermoplastic polyurethane composites." Polym. Degrad. Stab, Vol. 65, pp. 47-51.

[10] Pinto, U. A., Visconte, L. LY., 2001, "Mechanical properties of Thermoplastic Polyurethane elastomer with mica and aluminium trihydrate." Eur. Polym. J, Vol. 37, pp. 1935-1937.

[11] Gan, D., Lu, S., Song, C., Wang, S., 2001, "Mechanical properties and frictional behavior of mica filled Poly (aryl ether ketone) composites." Eur. Polym. J, Vol. 37, pp. 1359-1365.

[12] Song, C., Wang, S., Gan, D., Lu, S., 2001, "Physical properties of Poly(ether ketone ketone)/mica composites." Mat. Lett, Vol. 48, pp. 299-302.

[13] Pastorini, M. T., Nunes, R. C. R., 1999, "Mica as a filler for ABS/Polycarbonate blends." J. Appl. Polym. Sci., Vol. 74, pp. 1361-1365.

[14] Joshi, A. D., 1993, "TPO vs PVC for automotive interior." J. Coated Fabrics, Vol. 23, pp. 67- 73.

[15] Parister, L. M., 1983, "Copolyester: The fuel resistant thermoplastic elastomer." $J$. Elastomer \& Plastics, Vol. 15, pp.146- 158.

[16] He, D., Jiang, B., 1993, "The elastic modulus of filled polymer composites." J. Appl. Polym. Sci., Vol. 49, pp. 617-621.

[17] Gahleitener, M., Neibl, W., 1994, "Correlation between Rheological and mechanical properties of mineral filled polypropylene composites", J. Appl. Polym. Sci., Vol. 53, pp. 283-289. 